\title{
CONSTRUÇÕES IDENTITÁRIAS EM “QUARENTA DIAS” (2014), DE MARIA VALÉRIA REZENDE
}

\author{
IDENTITY CONSTRUCTIONS IN “QUARENTA DIAS” (2014) BY MARIA VALÉRIA REZENDE
}

Mayara Stéphanie Barbieri dos Santos ${ }^{1}$

${ }^{1}$ Mestranda da Universidade Estadual de Maringá. may.barbieri@hotmail.com
SANTOS, M. S. B. dos. Construções identitárias em "quarenta dias" (2014), de Maria Valéria Rezende. Akrópolis Umuarama, v. 27, n. 2, p. 119-126, jul./dez. 2019.

DOI: 10.25110/akropolis.v27i2.7613

Resumo: Este artigo traz uma proposta de análise do livro "Quarenta Dias" (2014), de Maria Valéria Rezende, com escopo na questão do exílio e identidade da personagem principal, Alice. Nosso objetivo foi buscar entender alguns dos processos de construção de identidade a partir do exílio de Alice, pensando nos aspectos que impulsionam suas mudanças e as diferenças que podem ser observadas nela entre o começo de sua jornada e o final. Analisamos suas escolhas e comportamentos baseados em teóricos como Said (2003) e Nouss (2016) em relação ao exílio e o sentimento de exiliência, Bauman (2005), Reis (2015) e Silva (2009) no que toca as construções identitárias e, ainda, Veiga (2012), a respeito da mulher de meiaidade e sua identidade social. Aportados nesses estudiosos, pudemos verificar o caráter inconclusivo dos processos de construção identitária, o que pode ser visto na personagem de Alice, que, podemos apenas conjecturar, continua a construir-se e desconstruir-se, em um processo infinito de identidades.

Palavras-chave: Exílio; Exiliência; Identidade; Meia-idade; Mulher.

ABSTRACT: This paper analyzes the book "Quarenta Dias" (2014) by Maria Valéria Rezende, with focus on the matter of exile and identity of the main character, Alice. The author intended to understand some of the processes of identity construction from Alice's exile, and muse about the aspects that propelled her changes, as well as the differences that can be seem on her throughout her journey. The study analyzes her choices and behaviors based on Said (2003) and Nouss (2016) concerning her exile; Bauman (2005), Reis (2015), and Silva (2009) about her identity constructions; and Veiga (2012) regarding middleaged women and their social identity. With these scholars' contributions, it was possible to find the inconclusive aspect of the identity construction processes, which can be seen in Alice. One can only suppose that Alice continues to construct and deconstruct herself in an infinite process of identities.

KEYWORDS: Exile; Exilience; Identity; Middle-age; Woman. 


\section{INTRODUÇÃO}

Os escritos de Maria Valéria Rezende, ganhadora do prêmio Jabuti (2009; 2013; 2015), têm encantado leitores desde 2001, quando lançou "Vasto Mundo", aos 60 anos de idade. Seja por prazer, seja com objetivos acadêmicos, os livros de Rezende cativaram leitores por todo o país, e chamaram a atenção do grande público, assim como dos críticos literários.

"Quarenta Dias", publicado em 2014, conta uma porção da história de Alice, uma muIher nascida e criada na Paraíba, mas que é obrigada a largar casa e amigos por insistência da filha, Norinha, que mora em Porto Alegre e quer que a mãe se mude para perto e a ajude com sua futura criança. À princípio ela se recusa, entretanto, se sentindo insegura e desnorteada com a pressão que Norinha a submete, Alice acaba cedendo. Porém, ao descobrir que Norinha pretende estudar fora do país, ela decide fugir da casa fria e artificial que a filha montou para ela, fugir da vizinhança e da própria família. Ela se lança numa busca desesperada pelo filho de uma conhecida, Cícero Araújo, que teria desaparecido em algum local na periferia de Porto Alegre.

Partimos dos seguintes questionamentos para direcionar nossa análise: o que impulsiona as mudanças na personagem Alice? Como a jornada de Alice molda suas escolhas? Quais diferenças podem ser observadas nela entre o começo do percurso e o final? Assim, com tais perguntas em mente, o objetivo é buscar entender os processos de construção de identidade a partir do exílio da personagem Alice em "Quarenta Dias" (2014), de Maria Valéria Rezende.

\section{O EXÍLIO COMO PONTAPÉ INICIAL}

A questão do exílio é um ponto essencial em "Quarenta Dias" (2014). Na narrativa, a personagem de Alice vive em João Pessoa de forma tranquila, enfrentando seus problemas com inteligência sem pressa, sua calma perante os acontecimentos the conferindo uma sensação de pertencimento que não se reconhece no dia a dia, a não ser quando é arrancado de si.

Alice cria sua filha Norinha sem o pai, que, envolvido em políticas e protestos, desaparece um dia e não volta mais. Não há muitas explicações, mas Alice, como a mulher forte e implacável que demonstra ser, continua a viver.
Ela entende que não pode parar, e tenta dar uma vida digna, feliz, para sua filha por meio de seu exemplo cordial e delicado para com as circunstâncias. Norinha tem a oportunidade de escolher viver uma vida acadêmica, conhece o namorado Umberto e vai morar em Porto Alegre, no Rio Grande do Sul. Já no doutorado e aos trinta e poucos anos, Norinha faz uma proposta como um golpe: quer ser mãe e precisa que sua mãe a ajude. Ela quer que Alice vá morar em Porto Alegre para ser "avó profissional". Alice diz não, e a partir da recusa, Norinha faz uso de artifícios inesperados para convencê-la. Ela acusa a mãe de a ter condenado a viver uma vida de solidão, sem irmãos, a chantageia em tom amargo e acusatório por dias e dias. Quando isso não dá certo, manipula o resto da família para que também tentem convencer Alice a se mudar. Ela acaba cedendo a pressão, e a vergonha lhe invade. Esse é o momento do xeque-mate:

Aquela canseira foi me amolecendo, dia a dia, me dando uma desistência, e nem lembro direito se foi a própria Norinha ou sua aliada-mor, Elizete, quem me arrochou num canto da parede: Você vai para Porto Alegre, sim, e não se discute mais isso, todo mundo vê que é o meIhor, é sua obrigação acompanhar sua filha única, só você é que não aceita, parece um jumento empacado na lama, continuar com uma besteira dessas.

Eu cedi, vergonhosamente. Foi isso. O resto é consequência. (REZENDE, 2014, p. 34).

É a partir daí que começa sua experiência como exilada. Said, teórico palestino, afirma que o exílio "é uma fratura incurável entre um ser humano e um lugar natal, entre o eu e seu verdadeiro lar: sua tristeza essencial jamais pode ser superada" (2003, p. 46). Essa definição é muito bem representada em "Quarenta Dias" (2014), principalmente quanto ao motivo do não-pertencer de Alice: a própria filha. Para ela, a imagem que sempre tivera de sua filha é brutalmente alterada, pois ela não fazia ideia que Norinha fosse capaz de lhe impor tamanha mudança. Depois de muito protelar, como se tomando coragem, Alice admite como o egoísmo de sua própria filha lhe dói, como ela lhe parece uma desconhecida.

A imagem de lar, mencionada por Said (2003), não precisa ser necessariamente uma 
estrutura, uma casa pregada no chão, mas pode ser o próprio chão. Lugares, pertences. Ou pessoas. Mesmo que sua filha já morasse do outro lado do Brasil, os laços familiares entre mãe e filha são, ou espera-se que sejam, fortes e duradouros. Alice sofre muito ao não reconhecer o sentimento que nutria por sua filha refletido nela; o que vê, na verdade, é egoísmo por parte de Norinha. Além disso, vê amargura e ressentimento, sentimentos que ela não sabia que estavam sendo nutridos, e que, com o pedido de Norinha e sua subsequente recusa, vêm à tona. E então há ruptura. Essa é a primeira, a ruptura com a ideia de lar depositada na pessoa da filha, mediante pedidos infundados - ou fundados em senso comum - e ressentimento.

As seguintes rupturas com seu lar vêm após Alice ceder à filha. Começa, a partir de então, o expurgo de seus pertences. Ela é chamada de "velhota sentimental" por se apegar aos seus livros, suas roupas, seus móveis. O que não foi para dentro de caixas para serem transportadas para Porto Alegre, foi para brechó, foi vendido, foi jogado fora. Alice fica, "à derrocada de sua vida tão boínha" (cf. REZENDE, 2014, p. 8), como ela mesmo diz, assistindo ao desmanche de seu lar. Seu exílio começa antes mesmo de sair de João Pessoa. Despojada de seu lar, Alice sente-se oca, reiterando o que afirmou Nouss (2016): "de propriedade sua, o exilado tem apenas o corpo e os actos" (p. 61).

Em geral, as pessoas exiladas são expulsas de seus países por intolerância racial, religiosa ou política. Algumas pessoas são obrigadas, em condições precárias de subsistência, a abandonar seus lares e peregrinar em busca de algum lugar onde possam recomeçar. Segundo Said (2003), entre as pessoas que se encontram nesse lugar de não-pertencimento, não estão somente os exilados, mas também refugiados, expatriados e emigrados. O exílio tem origem no banimento, os refugiados fogem de seus estados políticos, expatriados moram voluntariamente em outro país, enquanto os emigrados sofrem de uma situação ambígua, pois podem ter ido para outro país por escolha ou por pressão de um motivo ou outro. Pois então, mesmo que Alice tenha dito, de sua própria boca, "sim" para Norinha, não podemos considerar sua mudança como uma escolha, mas como um banimento. Ela foi exilada não por intolerância, nem por perseguição política, muito menos por necessidade - mas pela ideia baseada no senso comum de sua filha de que há alguma obrigação das avós em ajudar a criar seus netos.

Sobre essa incongruência, o teórico Nouss (2016) discorre sobre o conceito de exiliência, um neologismo - que não fala de passividade - e que, segundo nossa leitura, pode se encaixar na situação vivida por Alice. Ele escreve que a exiliência escapa a fatores externos:

Núcleo existencial comum a todas as experiências de sujeitos migrantes, quaisquer que sejam as épocas, as culturas e as circunstâncias que as acolhem ou que as provocam, a exiliência declina-se em condição e consciência, podendo inclusive acontecer que as duas, em graus distintos, não coincidam: pode alguém sentir-se em exílio sem ser concretamente um exilado (consciência sem condição), como pode alguém ser um exilado em concreto, sem contudo sentir-se em exílio (condição sem consciência) (NOUSS, 2016, p53).

Alice não passa por uma ditadura militar, não sofre repressão, ela não é expulsa do país, sua religião não é perseguida, ela não é uma mulher pobre. Quando se vê obrigada a sair de João Pessoa, ela não está em busca de uma vida melhor, oportunidades de trabalho, sonhos de crescimento pessoal ou financeiro. Mesmo assim, a consciência de exílio lhe persegue e Ihe domina, colocando-a nesse lugar injusto de não-pertencimento, mesmo que esteja no mesmo país, livre para ir e vir e com boas condições em termos financeiros.

Quando Alice chega em Porto Alegre, Norinha já havia preparado um apartamento para ela. Sobre isso, Alice escreve: "Enquanto ali se desmontavam minha cabeça, minha casa, minha vida, cá no Sul Norinha montava, à maneira dela, ao gosto dela, o que eu havia de ter e ser no futuro próximo" (REZENDE, 2014, p. 37). Esse apartamento é decorado de forma muito moderna, branco e preto, com poltronas, prateleiras, um tapete felpudo e objetos geométricos para decoração. Alice descreve os objetos como sem sentido, sem nexo, sem história. Segundo Nouss (2016, p.63) “(...) o exilado vê-se excluído dos quadros mentais e culturais que lhe ofereciam referência e conforto". Não só sua casa e seus pertences, mas Alice menciona seus veIhos e novos amigos, a praia, seus planos, seus livros e roupas. Mais tarde, ela estranha as pes- 
soas, que lhe parecem estrangeiras, tão altas, de peles claras, com sotaque diferente, dialeto e costumes diferentes, terra de clima e cultura tão distintos do que estava acostumada. Todo o seu aconchego é substituído por estranheza, pelo estrangeiro; e ela se vê excluída das relações mentais, culturais e sociais que se fazem naquele novo lugar.

Depois de receber a notícia de que sua fiIha viajaria para Europa por pelo menos seis meses, Alice se prende no apartamento e ignora as ligações de Norinha e suas tentativas de vê-la. É nessa situação que sua prima Elizete telefona e introduz um elemento decisivo para a narrativa: ela conta que uma mulher chamada Socorro precisava de ajuda - ela tem um filho chamado Cícero Araújo que havia ido trabalhar em Porto Alegre e nunca mais deu notícias. Ela pede que Alice tente ajudar. Alice usa essa oportunidade para sair daquele apartamento sem aconchego para andar por Porto Alegre para tentar encontrar Cícero Araújo.

Durante o percurso de Alice em busca de Cícero Araújo, as condições de seu exílio vão sendo alteradas. Antes, ela cultivava a imagem de Porto Alegre como uma cidade fria, com pessoas completamente diferentes dela, com um apartamento preto e branco sem qualquer elemento de intimidade ou conforto. Contudo, enquanto a jornada vai acontecendo, Alice passa a descobrir uma Porto Alegre distante da imagem que possuía. Ela descobre sulistas negros (o que Ihe é uma surpresa), descobre "vilas" (essencialmente, favelas), que ela define como "o avesso da cidade" (REZENDE, 2014, p. 235), descobre pessoas vindas de sua mesma região, e, aos poucos, ela vai percebendo as semelhanças entre os povos que, geograficamente, estão tão distantes.

Estranhezas, eu disse? Engraçado é que eu tinha a impressão de, afinal, quase nada ver de tão estranho assim, neste Sul tão longe de casa, o povo misturado de todas as cores, os petiscos de pobre, aquele tanto de negros gaúchos que eu nunca soube que existiam, violência e solidariedade, pobreza e necessidades, iguais às da minha terra, a pedir milagres. (REZENDE, 2014, p. 120).

A personagem encontra certo acalento quando tem a oportunidade de compartilhar de aspectos culturais ligados a sua própria terra.
O exílio pode oferecer, apesar de sua condição tenebrosa, alguns aspectos positivos, por exemplo, a pluralidade na visão de quem experiencia mais de uma cultura (cf. SAID, 2003). Porém, não são todos que conseguem se desprender a ponto de olhar para o lado positivo, afinal, como Said (2003) discute, a questão do exílio é complicada, contrapontística e descentrada. Alice, lançada em uma situação sem volta, percebe aquilo que afirma Nouss (2016, p.63), "já não há roots [raízes] mas routes [caminhos] (...)." Ela usa suas andanças e novas vivências para analisar novas perspectivas, abrir o olhar para outros caminhos, buscar identificação com o diferente.

Em sua peregrinação em busca de Cícero Araújo, Alice encontra solidariedade, bondade, solicitude e percebe que nem tudo é frio em Porto Alegre. Segundo Nouss (2016, p.96-97), o exilado, o excluído, o marginal, por estar sempre em confronto com o que é injusto, possui uma resistência ao desumano. É essa realidade que Alice encontra nas brechas mais invisíveis da periferia de Porto Alegre; foi o convívio com essa gente que a torna, pouco a pouco, menos desesperada e mais segura de quem é. Nouss (2016, p.85) ainda afirma que "numa perspectiva psicológica elementar, mesmo aquele que regressa nunca é aquele que partiu (...)", o que acontece com Alice. Suas identidades são chacoalhadas e repensadas e reconstruídas em um período bastante curto de tempo.

\section{AS IDENTIDADES DE ALICE}

Como lidar com o trauma de ser "arrancada" de sua própria casa, por alguém de sua família? Alice encontra sua maneira: ela escreve. Durante o expurgo de seus pertences, Alice se agarra em um caderno da Barbie que tinha em casa e se recusa a jogá-lo fora. Ela o descreve como sendo um caderno velho, com trezentas folhas amareladas e com a moldura rosa, com a Barbie na capa. Sua escrita é toda direcionada a Barbie - a boneca se torna seu interlocutor. Logo no começo do livro, ela escreve que "o caderno veio na minha bagagem por pura teimosia, mas com um destino oculto, tábua de salvação pra me resgatar do meio dessa confusão que me engoliu." (REZENDE, 2014, p. 9).

Alice escreve sua história para Barbie depois que os quarenta dias (do título do livro) já haviam passado, tempo este que ela havia 
procurado Cícero Araújo na periferia de Porto Alegre. Quando a narrativa começa, ela está em burburinho - a própria estrutura do livro pode ser demonstrativa dessa interpretação, com a falta de pontuação, frases deixadas pela metade, pensamentos embolados em outros, sem vírgulas, sem pausa para respirar. Ela adiciona em seu caderno alguns folhetos, recibos, papeis que tinha no fundo da bolsa ao chegar ao apartamento, assim como citações de livros que gosta.

Sua escrita começa descrevendo o momento em que sua filha e prima começam a se livrar de seus pertences e continua a narrativa sobre a mudança para a capital do Rio Grande do Sul, sua (não) adaptação, sua jornada em busca de Cícero Araújo e seu retorno ao apartamento preto e branco. Durante esse período em que ela escreve, recém-chegada de seus dias vivendo na rua, o ato de escrever vai lhe acalmando a mente, ordenando seus pensamentos e sentimentos, tratando suas feridas. Ela exclama: “(...) não quero cozinhar nem nada, não quero pôr ordem nas coisas, quero pôr ordem em mim, quero mesmo é escrever" (REZENDE, 2014, p. 46). A escrita terapêutica de Alice nos permite um vislumbre nas grandes mudanças que aconteceram com ela, com suas identidades.

Bauman (2005) problematiza a comparação da busca por uma identidade com a construção de um quebra-cabeças. Ele discorre sobre a analogia, pensando as identidades como quebra-cabeças incompletos, com peças faltando, sem um número exato de peças, sem uma caixa com a imagem final impressa a qual se deve reproduzir, sem destino nem trajeto predeterminado. $O$ autor afirma que:

No caso da identidade (...), o trabalho é direcionado para os meios. Não se começa pela imagem final, mas por uma série de peças já obtidas ou que pareçam valer a pena ter, e então se tenta descobrir como é possível agrupá-las e reagrupá-las para montar imagens (quantas?) agradáveis. Você está experimentando com o que tem. Seu problema não é o que você precisa para "chegar lá", ao ponto que pretende alcançar, mas quais são os pontos que podem ser alcançados com os recursos que você já possui, e quais deles merecem os esforços para serem alcançados. (BAUMAN, 2005, p. 55)
Isto é, as identidades não são prontas, não há uma resposta fácil para a pergunta "quem é você?", visto que ela depende dos meios que se tem disponíveis, assim como das oportunidades e recursos que lhe são apresentados. Para Reis (2015), que faz um estudo sobre identidade vista através do olhar de alguns teóricos, a identidade pessoal, para Bauman, é definida na e pela história. Ou seja, os indivíduos não teriam autonomia de determinar quem são, já que essa informação é condicionada atualmente. No passado, nos séculos XIX e XX, a modernidade era sólida, as identidades eram dadas - nascia-se com elas e morria-se com elas - e impostas pelo Estado Nação, que impunha uma uniformização forçada (cf. REIS, 2015, p. 88). A partir do fim do século XX e agora no XXI, a modernidade sólida se liquefez, e as identidades se tornaram um oximoro, de acordo com Reis (2015, p. 92), uma "escolha imposta". Essa contradição se faz dado que, hoje, a identidade pessoal se tornou revogável e negociável, algo a ser inventado para se encaixar no mercado, por isso, uma escolha, mas uma escolha forçada pelas condições da sociedade-mercado característica da modernidade líquida.

Pensando na situação encarada por Alice, em sua realidade em João Pessoa, sua identidade lhe parecia muito natural, predeterminada, inegociável. Ela se identificava com alguns rótulos, como o de "Prof. Póli", que, segundo ela mesma, era "tão honesta e certinha" (REZENDE, 2014, p. 104). Alice era uma professora de francês que pede a segunda aposentadoria quando cede às pressões de Norinha. Ao chegar em Porto Alegre, como Bauman discute, ela se sente deslocada, sem nenhum lugar em que se sentisse ajustada (cf. BAUMAN, 2005, p. 18). $E$, segundo o autor, quando a imagem de identidade irrevogável, estável pelas âncoras sociais, cai por terra, "a 'identificação' se torna cada vez mais importante para os indivíduos que buscam desesperadamente um 'nós' a que possam pedir acesso" (BAUMAN, 2005, p. 30). Pode ter sido com esse sentimento, com essa motivação escondida, essa busca por um 'nós' a qual pertencer, que Alice sai do apartamento preto e branco a procura de Cícero Araújo.

A sua jornada identitária em Porto Alegre começa no apartamento preto e branco, quando ela precisa pedir para o porteiro do prédio uma recomendação de diarista. A primeira pessoa que aparece olha para Alice, inventa uma des- 
culpa e vai embora. A segunda pessoa, Milena, é "brasileirinha" como Alice:

Dona Alice, estou mandando aí pra senhora uma diarista que, essa sim, a senhora vai gostar demais e tenho certeza de que ela vai ter tempo e querer the servir, vão se dar bem, que ela é brasileirinha, assim como a senhora. Agradeci e fiquei ali parada com o interfone na mão, esquecida de desligar, intrigada com aquilo, brasileirinha feito a senhora?, que conversa era aquela? (...) $\mathrm{Eu}$, no fundo contente de ter companhia da minha própria espécie. (REZENDE, 2014, p. 66-67)

Milena era baiana. Ela é a primeira pessoa em Porto Alegre com quem Alice 'se identifica', como postula Bauman (2005). A identidade de "brasileirinha" que lhe é imposta pelo meio social em que se encontra acaba por ser uma identificação. Ela percebe seu deslocamento junto às pessoas sulistas, e aqueles mais ao norte do território brasileiro se tornam todos mais ou menos a sua comunidade, a sua "própria espécie". Essa característica se interliga a outra construção identitária dada a ela pelos porto-alegrenses: ela se torna "de lá".

Eu, confundida de todo, querendo explicar que era Paraíba, nada a ver com Recife, Fortaleza, Bahia, Minas, que Cícero era brasileirinho feito eu, que trabalhava em obra de construção, mas foi inútil, Pois então, não é isso mesmo, de lá? "Lá" parecia ser um vago território homogêneo que cobria tudo o que fica acima do Trópico de Capricórnio. (REZENDE, 2014, p. 110-111).

As identidades de Alice, em constante mudança, são, como Reis (2015) caracteriza, uma "escolha imposta". Com o intuito de não se sentir tão deslocada em seu exílio, ela busca identificação, mesmo que nunca se sinta 100\% ajustada, há a tentativa de encontrar aqueles de sua "própria espécie", como já havia encontrado em Milena. Ela percebe que, de acordo com a representação das pessoas que são de Porto Alegre, sua identidade se resume a simples expressão "de lá". Essa simples expressão pode demonstrar a diferença entre as comunidades sociais que ali (nas vilas que ela visita) se encontram - todos pobres, todos periféricos, todos buscando se ajustar, mas ainda com a divisão dos "de lá" e, por consequência, "dos daqui".

Segundo Silva (2009), a identidade não deve ser vista como autossuficiente, como se fosse um fato autônomo. A diferença e a identidade possuem uma relação de estreita dependência, pois a identidade não parte de si mesma, mas da diferença (por exemplo: "sou brasileira", o que denota eu não ser francesa, alemã...) e tudo que é diferente, o é em relação a uma identidade, por exemplo: "ela não é daqui", o que a coloca como diferente de mim. Identidade e diferença são inseparáveis. Para Alice, ser "de lá" não só a difere dos "daqui", mas a coloca em um grupo, lhe impõe uma identidade nova.

Falar em identidades impostas implica dizer a identidade e a diferença são dependentes da representação. Silva (2009) entende a representação a partir de uma perspectiva pós-estruturalista, em que, como qualquer sistema de significação, a representação é uma forma de atribuição de sentido. Isto é, lidamos com instâncias arbitrárias, indeterminadas e ligadas a relações de poder. O autor diz destaca "quem tem o poder de representar tem o poder de definir e determinar a identidade" (SILVA, 2009, p. 91). Alice passa por isso não só com o "poder de representar" das pessoas que nasceram em um lugar no qual ela acabou de chegar, mas com a própria filha, Norinha, que lhe impõe uma identidade que a própria Alice não esperava ou cogitava. A ideia de "avó profissional", que ela mesmo menciona.

O pedido de Norinha para que sua mãe se mude para ajudá-la a criar o futuro neto é baseado na ideia de que a vida de uma pessoa de meia-idade, uma pessoa que passa dos 50 anos, acabou, não serve mais para ela mesma, mas somente para sua família. De acordo com as reflexões de Veiga (2012), quando a representação do corpo feminino está tão associada à beleza e à juventude, "a velhice, assim, seria o impuro, a mácula, a sujeira, o pecado" (p. 71). Segundo a autora, que discorre sobre as mudanças físicas, psicológicas e sociais que ocorrem na meia-idade feminina, tais mudanças são deflagradas por processos culturais e sociais, porém, são naturalizadas e até mesmo normatizadas e hegemonizadas como crises (cf. VEIGA, 2012, p. 72). A sobrevalorização das idades que antecedem o amadurecimento e a velhice também influenciam nessa concepção. Ela comenta que, "curiosamente, as idades e os ritos de pas- 
sagens são bastante demarcados até a chegada à vida adulta para, em seguida, irromper ladeira abaixo, num processo de franca decadência e desmoralização." (VEIGA, 2012, p. 73), como se a chegada dos 40 anos em diante mostrariam um declínio inevitável.

Norinha parece pensar que a vida de Alice não vale tanto quanto a dela, que é jovem e pretende ser mãe. Alice comenta, sobre a atitude da filha, "o certo pra ela era que eu, afinal, já tinha chegado ao fim da minha vida própria, agora o que me restava era reduzir-me a avó." (REZENDE, 2014, p. 26). "Avó" pode ser uma identidade imposta a mulheres que chegam à velhice, quer elas sejam ou não, quer elas queiram ou não, pelo simples fato de terem alcançado a idade "designada" para cumprirem tal papel social. Alice pede a segunda aposentadoria para ir para Porto Alegre, o que é outra construção identitária para lidar. Ela não está mais dando suas aulas de francês; após voltar de sua jornada nas ruas, escreve para Barbie: "Eu, agora, sopinha, novelinha, caminha, uma senhora aposentada, conformada e solitária como outra qualquer" (REZENDE, 2014, p. 141), o que é mais uma peça do quebra-cabeças incompleto e infinito de sua construção identitária. Uma escoIha imposta: escolhe-se aquilo que a sociedade espera dos indivíduos.

Alice se encontra, de repente, como o lugar do diferente, "qual andorinha sem ninho" (REZENDE, 2014, p. 167), em uma transitoriedade característica daqueles dos quais as âncoras sociais foram arrancadas. Ela se compara com a sua xará literária, do livro "Alice no País das Maravilhas", de Lewis Caroll, quanto à imprevisibilidade de sua vida quando se torna uma andarilha na periferia de Porto Alegre. A identificação que tanto busca é encontrada em maior grau nas ruas do que no apartamento branco e preto, ou em companhia de sua própria filha. Nas ruas, ela percebe que:

(...) a cabeça finalmente livre pra me dar conta de ter-me metido numa espécie de aventura e, como minha xará despencando por um poço a parecer sem fundo, sem vontade nenhuma de parar, porque desde aquela manhã, no meio da agitação que eu mesma causara com a minha pergunta, vinha ganhando uma calma por dentro que havia muito não sentia, as falas, emoções e estranhezas do mundo maior me chamando pra fora e a minha própria amargura encolhendo-se num canto discreto. (p. 120)

Quando ela se deixa imergir na aventura de buscar Cícero Araújo, quando ela se deixa guiar por pessoas desconhecidas, mas que buscam ajudar, quando ela percebe que não sabe o endereço do apartamento preto e branco de cor e se deixa se perder, de alguma forma, Alice se encontra. Não que ela tenha encontrado uma identidade estável, nem que ela esteja finalmente 'ajustada', mas ela se identifica com o burburinho do lado de fora - o burburinho da favela, das pessoas, das culturas entrelaçadas, das saudades: esses burburinhos se parecem com o seu. E ela se deixa cair no buraco do coelho branco.

Depois que os seus quarenta dias de peregrinação passaram, Alice retorna para o apartamento e escreve, tentando assentar todas as novas experiências, as novas perspectivas, bem no meio de um fluxo particularmente intenso do processo de construção e desconstrução identitária.

Conforme Alice escreve, a inquietude frenética que sentia vai se acalmando. $O$ que antes era escrito sem pontuação, sem pausa para respirar, como se ela tivesse se debruçado no caderno e se esforçado para jorrar tudo o que precisava pôr para fora, passa a ter mais coesão, mais calmaria. Mesmo assim, quando ela sente que não precisa mais escrever, ela termina sem ponto final:

Chega, Barbie, agora eu paro mesmo, que já está clareando o dia. Agradeço a paciência, guria, a solidariedade silenciosa, mas agora vou te trancar numa gaveta, tu não leva a mal, tá?, não digo que seja pra sempre, quem sabe ainda reabro estas páginas, passo tudo a limpo (REZENDE, 2014, p. 245).

Esse final é especialmente característico das identidades em constante mudança, em constante (des)construção. Alice se sente mais tranquila com quem é, com quem se tornou, após sua aventura procurando Cícero Araújo, que na verdade foi realmente uma aventura procurando a si mesma. Nesse último parágrafo, ela até mesmo chama Barbie de "guria", palavra que antes aparecia somente da boca de personagens porto-alegrenses, como marca de uma diferença intransponível. A diferença ainda existe, mas não lhe parece mais abissal. Talvez, o momento que ela decide parar de escrever, seja 
um momento em que o burburinho silenciou, não completamente, mas talvez o suficiente.

\section{CONSIDERAÇÕES FINAIS}

A questão identitária de Alice em "Quarenta Dias" (2014) é como deve ser: inconclusiva. Não temos informação sobre o futuro de Alice, se ela se conforma com a identidade de avó profissional, se ela sente a necessidade de sair em aventuras andarilhas, se ela se identifica com Alice, a do país das maravilhas, que escoIhe cair pelo buraco do coelho.

Muitas possibilidades são levantadas. Talvez Alice tenha se tornado escritora, ou avó profissional. Talvez ela se identifique com o rótulo de "brasileirinha", por se tratar de gente de sua mesma "espécie", mas talvez ela se deixe agauchar, falando "guria" e tomando chimarrão. Talvez os dois. Tudo isso não passa de hipóteses possíveis, que não constituem, de forma alguma, certezas. A ideia de identidade compreende "uma tarefa a ser realizada, e realizada vezes e vezes sem conta, e não de uma só tacada" (BAUMAN, 2005, p. 18). Não temos acesso ao que aconteceu depois, porém, podemos conjecturar uma Alice que continua a construir-se e desconstruir-se, em um processo infinito de identidades.

\section{BIBLIOGRAFIA}

BAUMAN, Z. Identidade: entrevista a Benedetto Vecchi. Tradução: Carlos Alberto Medeiros. Rio de Janeiro: Zahar, 2005.

NOUSS, A. Pensar o Exílio e a Migração Hoje. Tradução e nota de abertura: Ana Paula Coutinho. Porto: Edições Afrontamento, 2016.

REIS, J. C. Identidade e complexidade: Ricoeur, Nietzsche, Bauman. Revista Eletrônica-Expedições/Expeditions: Teoria da História e Historiografia. Morrinhos/GO. (ISSN 2179-6386). v. 6, n. 2, p. 69-93, agosto/dezembro. 2015.

REZENDE, M. V. Quarenta Dias. Rio de Janeiro: Objetiva, 2014.

SAID, E. W. Reflexões sobre o exílio: e outros ensaios. Tradução: Pedro Maia Soares. São Paulo: Editora Companhia das Letras, 2003.

SILVA, T. T. da. A produção social da identidade e da diferença. 2009. In: SILVA, Tomaz Tadeu da; HALL, Stuart; WOODWARD, Kathryn. (Org.). Identidade e Diferença: A Perspectiva Dos Estudos Culturais. 9. ed. Petrópolis, RJ: Vozes, 2009.

VEIGA, M. R. M. Mulheres na meia-idade: corpos, envelhecimentos e feminilidades. Santa Maria: UFSM, 2012. 117 p. Dissertação (Mestrado) - Programa de Pós-Gradução em Ciências Sociais, Universidade Federal de Santa Maria, Santa Maria, RS, 2012.

\section{CONSTRUCCIONES IDENTITARIAS EN “CUARENTA DÍAS" (2014), DE MARÍA VALÉRIA REZENDE}

Resumen: Este artículo trae una propuesta de análisis del libro "Cuarenta Días" (2014), de María Valéria Rezende, con énfasis en la cuestión del exilio e identidad del personaje principal, Alice. Nuestro objetivo ha sido buscar entender algunos de los procesos de construcción de identidad a partir del exilio de Alice, pensando en los aspectos que impulsan sus cambios y las diferencias que pueden ser observadas en ella, entre el comienzo de su jornada y el final. Analizamos sus escojas y comportamientos basados en teóricos como Said (2003), y Nouss (2016) en relación al exilio y el sentimiento de exiliencia, Bauman (2005), Reis (2015) y Silva (2009) en lo que se refiere a las construcciones de identidades y, aún, Veiga (2012), a respecto de la mujer de mediana edad y su identidad social. Aportados en esos estudiosos, se pudo verificar el carácter no concluyente de los procesos de construcción identitaria, lo que puede ser visto en el personaje de Alice, que, podemos solamente conjeturar, continua a construirse y desconstruirse, en un proceso infinito de identidades. Palabras clave: Exilio; Exiliencia; Identidad; Mediana Edad; Mujer. 